\title{
HAROLD GARFINKEL: \\ LA ETNOMETODOLOGÍA
}

Por Alejandra Fuentes G.

\section{INTRODUCCIÓN}

En 1968, Harold Garfinkel, bajo el rótulo de etnometodología, creó una nueva disciplina, concerniente a cómo el hombre organiza su vida diaria en sociedad, y también cómo hace que sus actividades sean significativas para él y para los otros individuos.

Procura comprender la situación social "desde adentro", tal como aparece a los hombres que la viven; trata de transmitir el sentido que tienen ellos de las cosas, evitando en especial las conceptualizaciones convencionales de la sociología normal; lo que no significa que no esté influido por ellas.

En efecto, al analizar los orígenes de la etnometodología encontramos la influencia de varias corrientes sociológicas. En primer lugar la fenomenológica, cuya importancia es fundamental. Incluso aunque algunos autores piensen que ésta sea una filosofía agonizante (Giddens: Las nuevas reglas de/ método sociológico, p. 34, 1987), podría señalarse que su presencia en Garfinkel y en la etnometodología es notable; como también lo es la de la denominada "filosofía del lenguaje ordinario", asociada con Austin y otros filósofos de postguerra de Oxford.

Ambas parecen converger en el estudio de la vida cotidiana, el mundo del lego en oposición al mundo del científico. La fenomenología insiste en que no se debe ridiculizar o menospreciar la "actitud natural" tal como lo hacen la mayoría de las tradiciones filosóficas más antiguamente establecidas, y sobre todo la filosofía positivista. Por el contrario, el sentido común es un depósito de ideas y prácticas al que hay que recurrir para refutar algunos errores y extravagancias de filósofos anteriores.

Sin embargo, parece que fueron los escritos de Schutz (el estudioso a quien se le atribuye haber mostrado la importancia de la fenomenología de Husserl para las 
ciencias sociales) los que proveyeron del estímulo inicial a Garfinkel para desarrollar sus ideas, aunque éste reconociera también su deuda con Parsons. Como a este autor, a Garfinkel le interesan profundamente los requisitos del orden social. Pero a diferencia de aquél, no asigna importancia especial al papel de la reciprocidad de las gratificaciones o de los valores morales compartidos. En cambio, y de un modo más durkheimiano, Garfinkel se interesa por el nivel cultural, $y$, en particular, por un tipo de "conciencia colectiva" secularizada. Influido por la fenomenología de Schutz, dedica principalmente su atención a la estructura de las reglas y el conocimiento compartidos y tácitos, vale decir inexpresables, que hacen posible una interacción social estable. Según Garfinkel, pues, lo que cohesiona el mundo social no es una moralidad con un matiz sagrado, sino una densa estructura colectiva de entendimientos tácitos (aquellos que los hombres saben y saben que los demás saben) referentes a los asuntos mundanos y "triviales" entendimientos a los cuales, si se los advierte, no suele atribuirse ninguna importancia especial, y mucho menos significación sagrada.

De este modo, la etnometodología "llega" a las ciencias sociales y a la sociología con un basamento teórico, pero por sobre todo con un punto de vista nuevo $y$, por qué no decirlo, original, de cómo debe enfrentarse el estudio del hombre en sociedad.

En este trabajo lo que se pretende es adentrarse en el estudio de las formulaciones etnometodológicas, además considerar sus vinculaciones con disciplinas como la lingüística y la sociología, aparte de realizar un análisis crítico de sus planteamientos. La tarea propuesta no resulta fácil no sólo por el desconocimiento del tema, sino también por la escasa bibliografía que existe al respecto. En todo caso, y pese a las dificultades, la misión a realizar parece de un gran interés y lo que se pretende es llevarla a cabo con éxito.

\section{¿QUÉ ES ETNOMETODOLOGÍA?: EL ORIGEN DEL TÉRMINO}

Para internarnos en el tema que nos interesa, resulta primordial la realización de un estudio extenso de lo que la etnometodología es. En este sentido es de fundamental importancia reconocer que en la etnometodología lo que se supone que es tarea de la ciencia social comprender, pasa a ser lo que se podría llamar selectivamente cognitivo (a diferencia de lo que sucede en Husserl y Schutz, en donde es predominantemente cognitivo), a saber, especializado en el método; se convierte en una especialización metodológica. El propio Garfinkel relata:

“En el momento de compilar esos materiales (entrevistas con jurados, cuyas deliberaciones habían sido grabadas y transcritas sin que ellos lo sospecharan), imaginé la noción que está en la base del término 'etnometodología'. ¿Quiéren saber de dónde tomé este término? Trabajaba con los archivos etnológicos de Yale. Me sucedió examinar la lista de las áreas sin intención ninguna de 
descubrir un término así... y di con una sección: etnobotánica, etnofisiología, etnofísica. En mi caso, estoy frente a unos jurados que hacen metodología, pero que la hacen de una manera casual. No es una metodología que mis colegas pudieran apreciar si estuvieran buscando personal para el departamento de sociología.

Ahora, ¿cómo rotular entretanto aquel material, de manera que me permitiera identificarlo? ¿Cómo obtener un recordatorio de él? Así fue como se empleó al comienzo 'etnometodología'. 'Etno' parecia designar, de alguna manera, la disponibilidad, para un miembro, del conocimiento de sentido común de su sociedad, en tanto conocimiento de sentido común de 'lo que fuere'. Si se trataba de 'etnobotánica', guardaría alguna relación con su conocimiento y su aprehensión de lo que a juicio de los miembros eran métodos adecuados para abordar cuestiones botánicas. Alguien de otra sociedad, en este caso un antropólogo, reconocería éstas como cuestiones botánicas. El miembro emplearía la etnobotánica como fundamento adecuado de la inferencia y de la acción en el cuidado de sus propios asuntos, en compañía de otros como él. Se trataba simplemente de eso, y la noción de etnometodología o el término 'etnometodología' se entendían en ese sentido" (Harold Garfinkel, The origin of the term 'Ethnometodology', 1968).

La etnometodología "no es una empresa misteriosa", "no es un culto", "no se propone solucionar aflicción alguna de la sociología". Le pidieron a Garfinkel que explicara brevemente en qué consiste su tarea, y respondió:

"Nos interesa cómo la sociedad se cohesiona; cómo se hace eso; cómo llevarla a cabo; las estructuras sociales de las actividades cotidianas. Diría que estudiamos cómo las personas, en tanto son parte de ordenamientos cotidianos, emplean los rasgos de ese ordenamiento para hacer que tengan efecto para los miembros las características visiblemente organizadas. Eso es, si usted lo quiere saber de verdad sumariamente" (Harold Garfinkel, Simposio en Etnometodología, 1968).

Ocho años después, Garfinkel definió así el quehacer de la etnometodología:

“Tareas, materialmente fundadas, que procuran poner de manifiesto las cuestiones identificatorias del orden social" (Anales de Sociología Fenomenológica, 1977).

Especializarse en metodología predispone a descuidar otras cosas, sobre todo se dejan de lado los que pueden ser asuntos sustanciales. La metodología aborda las actividades prácticas de las personas, las circunstancias prácticas y el razonamiento sociológico práctico; las acciones prácticas; la vida cotidiana, cuyas "estructuras formales" es tarea del etnometodólogo discernir, "al tiempo que se abstiene de pronunciar juicio alguno sobre su carácter adecuado, su valor, importancia, necesidad, utilidad práctica, logros o consecuencias. Llamamos indiferencia 
metodológica a esta actitud de procedimiento" (Harold Garfinkel, Estructuras formales de las acciones prácticas, 1970).

Aquí, evidentemente, "indiferencia metodológica" significa indiferencia a consideraciones morales que pudieran estorbar la metodología aplicada por el etnometodólogo, si bien "indiferencia" parece un término excesivo; de cualquier manera, no hay inclusión teórica de consideraciones morales en la concepción de la investigación.

En los primeros estudios de Garfinkel esta indiferencia hacia las consideraciones morales, o evitación de ellas, es un rasgo sobresaliente.

"Se instruía a los estudiantes para que entablaran con un conocido o un amigo una conversación corriente, y sin dar señales de que lo solicitado por el experimentador era en cierto modo insólito, insistieran en que las personas aclararan el sentido de cada uno de los lugares comunes empleados... A estudiantes de los primeros años de la Universidad se les asignaba la tarea de pasar en su hogar de quince minutos a una hora observando las actividades que se realizaban, figurándose que ellos eran pensionistas... Se instruía a estudiantes para que trabaran conversación e imaginaran que los dichos de otras personas respondían a motivos ocultos que eran sus motivos reales, y obraran en consecuencia... A aspirantes a ingresar en la facultad de medicina se los sometía individualmente a una entrevista experimental de una hora. Como parte de su solicitud de ingreso... el experimentador se identificaba como representante de una facultad de medicina del Este que quería averiguar por qué la entrevista de ingreso a la facultad de medicina producía tanta tensión... Asigné a estudiantes la tarea de regatear el precio de mercaderías que lo tenían fijado... Se instruía a estudiantes para que seleccionaran a alguien que no fuera de su familia, y sin dar señales de que ocurría algo insólito, acercar su rostro al del sujeto hasta quedar casi nariz con nariz" (David Sudnow, Estudios en interacción social, 1964).

He aquí algunas reacciones

“Se producían estallidos de desconcierto y rabia de miembros de la familia... francas manifestaciones de ira y desagrado... Dos de ellos (los aspirantes a ingresar a la facultad de medicina) mostraron signos de intenso sufrimiento cuando advirtieron que la entrevista terminaba y los despedían sin confesarles el engaño" (David Sudnow, op. cit.).

La "indiferencia etnometodológica" en que Garfinkel insiste se extiende a temas, problemas, cuestiones (algo que necesita de descripción). El mundo del etnometodólogo es un mundo de pura cognición, algo que está destinado a la cognición; y el sujeto (incluido el propio etnometodólogo), es sólo un sujeto que conoce.

Ahora bien, existe una diferencia entre la "neutralidad" de Max Weber y la 
"indiferencia" de Garfinkel. En Weber, la "neutralidad valorativa" opera como separadora entre "ser" y "deber ser" y expresa su convicción de que la ciencia se ocupa exclusivamente del "ser" y sólo en ese campo es competente; por lo tanto, nada puede decir acerca de cómo debería ser una sociedad buena o provista de sentido (como no se trate de la mera preferencia personal del científico). En cambio, en Garfinkel y casi toda la etnometodologia, la "indiferencia etnometodológica" hace las veces de una indiferencia hacia la cuestión misma del ser y el deber ser, incluida la búsqueda de una sociedad buena o provista de sentido.

Sería también interesante preguntarnos por la actitud del etnometodólogo hacia sus prójimos. Algo de esto vimos ya al hablar de la "indiferencia etnometodológica": el absorbente interés por la metodología de ellos y por su propia metodología, a expensas de la preocupación moral. No obstante, Garfinkel señala que la ciencia social tradicional, incluida la sociología, trata al miembro de la sociedad como "tonto sin discernimiento, de naturaleza cultural y/o psicológica" (con la expresión "tonto sin discernimiento" se refiere al hombre en la sociedad del sociólogo, que produce los rasgos estables de la sociedad al actuar en acatamiento a alternativas de acción preestablecidas y legítimas, que la cultura común proporciona. El "tonto psicológico" es el hombre en la sociedad del psicólogo, que lo hace por medio de opciones entre cursos de acción alternativos que son impuestos sobre la base de la biografía psiquiátrica, la historia condicionante y las variables de funcionamiento mental). Si el sociólogo tradicional sabe mejor que las personas a quienes estudia cómo son las cosas, el etnometodólogo no mantiene relación alguna con sus sujetos porque ellos son exclusivamente cognitivos. Pero esto significa que no son sujetos, sino sólo agentes, que por añadidura "ejecutan", "logran", se empeñan en establecer y mantener el orden social.

\section{a) Acerca de la racionalidad}

Garfinkel distingue entre la "racionalidad de la ciencia" y la racionalidad del sentido común, o de la "actitud natural". Con esto se refiere explícitamente al punto de vista weberiano acerca de la acción racional, abarcando la aplicación de criterios netos sobre la relación medio-fin a la explicación de la conducta humana. Desde este ángulo, la acción motivada se explica en función de los criterios del observador, que pueden ser y normalmente son muy divergentes de los utilizados por los actores mismos al orientar su conducta. Esto trae como consecuencia que amplias áreas de la actividad social humana aparezcan como "no racionales" y que las "acciones racionales" se consideren sólo como de significación marginal. Si abandonamos la idea de que hay una única norma de racionalidad que pueda ser aplicada a la interpretación de la conducta social, y hablamos, en cambio, de varias "racionalidades" que los actores son capaces de emplear, la acción racional deja de representar una mera categoría residual. Siguiendo a Schutz, Garfinkel distingue un número considerable de tales "racionalidades" que son relevantes para los 
intereses de la vida diaria antes que para los de las ciencias sociales. Por otra parte, los criterios de racionalidad que operan en estas últimas -que los conceptos deben ser precisamente definidos, tan generalizados como sea posible- no resultan de interés a los actores legos.

Como teórico social práctico, el actor lego se las arregla para ordenar su experiencia en forma de que la mantenga el supuesto de que el mundo (tanto natural como el social) es lo que parece ser, formulación que frecuentemente aparece en los escritos de Garfinkel en una u otra forma. "De un conjunto de relaciones posibles entre la apariencia actual del objeto y el objeto intencional, como, por ejemplo, una relación de dudosa correspondencia entre ambos, el agente espera que la correspondencia indudable presupuesta sea la correcta. De la otra persona aguarda que emplee la misma expectativa en forma más o menos idéntica, $y$, también exactamente como él, que la relación sea válida para la otra persona, del mismo modo en que éste espera que sea válida para él" (A. Schutz, "Sentido común e interpretaciones científicas de la acción humana", 1967). La actitud del observador científico social es la opuesta de ésta, e implica la suspensión de la creencia de que las cosas son como parecen ser, no está influido por las demandas pragmáticas que dominan la "actitud natural". Las dos actitudes, la del científico y la del lego, no se mezclan, sino que discrepan en forma radical: de ahí las dificultades surgidas al aplicar el tipo weberiano de modelo de la sociología interpretativa para la "comprensión" de la acción social.

La vida social, en cuanto vivida por sus actores, no debe verse entonces como una serie de débiles intentos de reproducir las normas de racionalidad tal como las especifica la "actitud científica", sino, muy por el contrario, como una serie de deslumbrantes realizaciones para las cuales estas normas son esencialmente ajenas. Entonces, lo que hace Garfinkel es concentrar su enfoque en las actividades cotidianas, en vez de hacerlo en los sucesos críticos o en espectaculares incidentes públicos. Considera a todas las personas como teóricos prácticos, que en colaboración crean significados y entendimientos de sus mutuas actividades. Su metodología presenta una tendencia fuertemente monista, ya que no establece ninguna diferencia radical entre los sociólogos y los demás hombres.

Si bien el punto de partida de tal exposición puede ser la fenomenología de Schutz, el resultado lleva en una dirección diferente. Garfinkel no demuestra interés por desarrollar el tipo de análisis motivacional que propicia Schutz, sino que se preocupa acerca de cómo la "actitud natural" es interpretada como fenómeno por los actores de la vida diaria. Según Garfinkel, la proposición subyacente de la etnometodología "es que las actividades mediante las cuales los miembros de la sociedad producen y manejan conjuntos de cuestiones diarias organizadas son idénticas a los procedimientos de esos miembros para hacer explicables aquellos conjuntos". Las prácticas sociales, según dice, "son realizadas bajo los auspicios de los mismos asuntos diarios que son descritos al organizarlas, y en las cuales las 
originan como eventos" ( $\mathrm{H}$. Garfinkel, Las propiedades racionales del cientifico y las actividades de sentido común, 1967).

\section{b) Las expresiones indexales como objetivo de la Etnometodología}

El estudio de la vida cotidiana o de los asuntos diarios, aleja a Garfinkel de la fenomenología, y lo inclina hacia el estudio de las "acciones situadas" como formas lingüísticas "públicamente" interpretadas. Al describir a éstas como objetivo de la etnometodología, Garfinkel procura recurrir sólo en raras ocasiones a terminología usadas por algunos filósofos anteriores, y utiliza en cambio los términos "indexalidad" y "expresión indexal", que toma de los escritos de Bar-Hillel, y derivan, en última instancia, de Peirce. Éste acunó originariamente la expresión "signo indexal" para referirse al hecho de que un signo puede tener diferentes significados en distintos contextos, y que los "mismos" componentes semánticos pueden ser expresados por signos distintos, de acuerdo con el contexto (y viceversa). Según Bar-Hillel, más del noventa por ciento de las oraciones-signos declarativas que una persona produce en el curso de su vida con expresiones indexales: "es evidente que la mayoría de las oraciones con tiempos de verbo, sin mencionar todas aquellas que contienen expresiones tales como 'yo', 'tu'', 'aqui', 'ahi', 'ahora', 'ayer' y 'éste'" (Bar-Hillel, Expresiones indexales, 1970). Tal como aparecen en el discurso corriente, esas expresiones son la materia misma con que la actividad social es organizada por sus miembros como una realización práctica, según sostiene Garfinkel; para los científicos sociales, no hacen más que obstruir la descripción de la actividad social. Casi todas las discusiones formales sobre el método de las ciencias sociales se ocupan de "remediar" las expresiones indexales, en un intento por volcarlas en formas que las liberen de su carácter indexal. Según Garfinkel, no es tarea de la etnometodología "reparar" las expresiones indexales. "Las expresiones indexales - escribe- no son exclusivas de las explicaciones de los legos. Son igualmente comunes en las explicaciones de los profesionales. Por ejemplo, la fórmula del lenguaje natural: 'La realidad objetiva de los hechos sociales es el principio fundamental de la sociología', los profesionales la escuchan, según la ocasión, como una definición de las actividades de los miembros de la asociación, como su lema, tarea, meta, realización, jactancia, lanzamiento de ventas, justificación, descubrimiento o impulso de investigación" (Garfinkel y Sacks, 1970).

El uso de expresiones indexales en el discurso ordinario implica que los actores sean capaces de utilizar un conocimiento que se da por supuesto, en función del cual están capacitados para ubicar su sentido. Este conocimiento no es nunca algo dado, sino que depende de la reflexividad de las explicaciones de los actores; éstas son elementos constitutivos de lo que tratan. Los actores sociales dan por sentada esta misma reflexividad en los otros, y hacen uso de este conocimiento para realizar "cualquier porción" de conducta social. "Los miembros conocen y requie- 
ren, cuentan con esta reflexividad y la utilizan para producir, realizar, reconocer o demostrar la adecuación racional para todos los propósitos prácticos de sus procedimientos y hallazgos" (H. Garfinkel, op. cit., 1967). En cualquier conversación entre dos o más personas, la "explicabilidad" de los fenómenos es obra de un trabajo mutuo de los participantes: ello puede ser entendido como un conjunto de prácticas glosadoras, por las cuales los hablantes en la situación particular del lenguaje expresan algo distinto de lo que pueden decir exactamente con igual número de palabras.

Todo esto parece presuponer también la existencia de ciertas reglas tácitas, un mundo social basado en tácitos entendimientos, los cuales, pese a su importancia como fundamento de todo lo demás, son frágiles y fáciles de eludir. En resumen, para Garfinkel los cimientos culturales son precarios y aparentemente su seguridad reposa, en cierta medida, en su invisibilidad o en el hecho que se los da por sentados. Cuando se vuelven visibles, sin embargo, pierden su firmeza con bastante facilidad. A diferencia de Parsons, Garfinkel no transmite ningún indicio de que los cimientos sociales posean una estabilidad inconmovible.

Garfinkel no examina las diferencias concretas en el carácter específico de esas diversas reglas tácitas. Dedica, en cambio, su principal atención a demostrar, primero, su existencia, y, segundo, el papel que cumplen proporcionando un sólido basamento para la interacción social. Como resultado de esto, cada regla así expuesta tiende a parecer un tanto arbitraria, ya que no se le asigna ninguna función especifica ni diferente importancia y es, en realidad, intercambiable con otras diversas, todas las cuales contribuyen de alguna manera a establecer el marco estabilizador de la interacción. Es plausible suponer que alguna otra regla podría cumplir con igual eficacia esta función estabilizadora. Por ende, su enfoque conduce a concebir esas reglas como convenciones, $y$, de este modo, a considerar la sociedad como algo dependiente de lo meramente convencional, o sea, de lo que son, en verdad, las reglas del juego. Garfinkel suele explicar dichas reglas mediante "demostraciones", similares a juegos, de lo que sucede cuando algunos hombres, sin enunciar a otros sus propósitos, proceden a violar deliberadamente esos entendimientos tácitos. $Y$ atribuye a todas las partes de la sociedad, incluyendo la ciencia (con su método riguroso), una dependencia respecto de esas reglas y procedimientos arbitrarios basados en el sentido común. Concibe la parte verdaderamente importante del mundo social como algo casi invisible, un mundo tan familiar que se lo da por sentido y pasa inadvertido. Garfinkel se plantea la misión de destruir este "dar por sentado" y despojar al cimiento cultural "del manto que lo hace invisible". No se dedica a ubicar los lugares comunes conocidos dentro de algún marco teórico, dotándolo así de un mayor significado y enriqueciendo con él la experiencia. Garfinkel aspira, sobre todo, a desnudar y desenmascarar el lugar común invisible.

Sin embargo, sería erróneo pensar que Garfinkel está interesado en develar 
aquellos cimientos culturales ocultos solamente, ya que sus investigaciones tienen lugar en gran medida en los "mundos en pequeña escala". Así, la obra de Garfinkel ataca al sentido común de la realidad.

\section{LA ETNOMETODOLOGÍA, LA LINGÜISTICA Y LA SOCIOLOGÍA}

El análisis de las expresiones indexales tiene claras e importantes implicaciones para la lingüística, en la que ha sido evidente desde hace mucho tiempo que la "semántica" no puede ser tratada en función de las propiedades estructurales del lenguaje considerado como un sistema abstracto y completo de "signos", "palabras" o incluso "oraciones". Se trata de un punto que ha recibido extraordinario impulso de los escritos de Wittgenstein, Austin y Ryle, y como consecuencia del abandono general de la idea asumida en una generación anterior por la teoría de Russell sobre las descripciones. Las ideas de Austin en particular y ciertas interpretaciones del Wittgenstein del último período tienden a recomendar un análisis descriptivo y detallado del significado de las palabras en el lenguaje corriente: principalmente, con el fin de resolver algunas cuestiones tradicionales de la filosofía. Así, se puede ver cierto sentido en la afirmación de Garfinkel de que los estudios últimos de Wittgenstein pueden entenderse bajo el aspecto de que examinan "las conversaciones de los filósofos como fenómenos indexales... y como una descripción de estos fenómenos sin intención de remediarlos" (Garfinkel y Sacks, 1970). Hay evidentes conexiones entre este comentario, que deriva de los objetivos de la etnometodología tal como los define Garfinkel, y la obra de recientes filósofos del lenguaje, que arribaron a la conclusión de que "la unidad de la comunicación lingüística no es, como se supuso generalmente, el símbolo, la palabra o la oración, ni siquiera el signo del símbolo, la palabra o la oración, sino más bien la producción o emisión del símbolo, la palabra o la oración en la ejecución del acto del lenguaje" extraído de A. Giddens. Las nuevas reglas del método sociológico, 1987). Pero la mayoría de tales filósofos y lingüistas parece tratar todavía las expresiones como el producto de actores individuales abstractos, o en forma alternativa, tal como se relacionan con reglas o convenciones lingüisticas igualmente abstractas, antes que como conversaciones situadas en el tiempo entre personas. La importancia de la diferencia, como lo indican los estudios de Garfinkel, Sacks, Schegloff y otros, puede ser notable. Los significados transmitidos por las expresiones son originadas en el proceso de conversaciones reales, mediante el modo en que el "trabajo conversacional" se realiza en una situación: hay partes de la conversación que son medios por los que la conversación misma, y de esta manera también los significados de sus expresiones componentes, es glosada o caracterizada.

Si lo dicho hasta ahora nos demuestra la importancia que las ideas de Garfinkel pueden tener para la lingüística, ¿qué se puede decir de sus relaciones con la sociología? Según lo declarado por el mismo Garfinkel, así como la filosofía deja al mundo tal como está, la etnometodología deja a la sociología tal como está. Nos 
dice, pues, que "los estudios etnometodológicos no están dirigidos a formular o discutir correctivos", que "aunque están dirigidos a la preparación de manuales sobre métodos sociológicos, no son en modo alguno suplementos para el procedimiento corriente, sino que son distintos de éstos", y que "no inician ni estimulan discusiones sobre la aplicación de la etnometodología" (H. Garfinkel, op. cit., 1967). Estas afirmaciones parecen llevar consigo dos aspectos. Primero, que el propósito de la etnometodología es hacer que la explicabilidad de las prácticas sociales sea explicable en sí misma, pero no "remediar" las expresiones indexales al modo de las teorías que tratan de clasificar y explicar estas prácticas en un nivel general. Segundo, que, en consecuencia, el etnometodólogo no diferencia, para el propósito de sus estudios, entre la sociología que los miembros legos de la sociedad realizan en el curso de su vida cotidiana y la sociología que realizan los científicos sociales profesionales (concepción monista ya antes desarrollada). A pesar de que estos últimos tienen un "programa de recetas" que es mucho más ambicioso que el de los anteriores, la ciencia social es una realización práctica igual a cualquier otra forma racionalmente explicable de actividad social, y puede ser estudiada como tal. En el caso de que esto llegue a aparecer como abogar por una especie de sociología de la sociología, Garfinkel declara que existen diferencias irreconciliables de interés entre lo que llamamos "análisis constructivo", o sociología ortodoxa, y la etnometodología, al parecer porque esta última debe limitarse al estudio de las expresiones indexales en toda su variedad empírica.

Dado que hay claras diferencias entre las ideas de Garfinkel y las de otros que adoptaron el término, la "etnometodología" no puede ser evaluada fácilmente como una totalidad. La actitud de "indiferencia etnometodológica", en la que insiste Garfinkel, no se mantiene con la imperturbabilidad que sería esperable si realmente existiera el abismo lógico que se supone hay entre la etnometodología y la sociología. Esto no debiera sorprender si se recuerda el papel que desempeñaron los escritos de Schutz, con su proyecto de "reconstituir" la sociología, como factor influyente sobre el desarrollo de las ideas de Garfinkel. Los trabajos de éste están en verdad plagados de observaciones sobre el análisis constructivo" y difícilmente muestran una actitud de indiferencia hacia él mismo. Hay un residuo bastante claro de la obra de Schutz, por ejemplo, en la observación de que "el mundo familiar del sentido común de la vida cotidiana ejerce una singular y obstinada soberanía sobre las pretensiones de los sociólogos de una explicación adecuada" (H. Garfinkel, Estudios en Etnometodología, 1967). De todos modos, la etnometodología, en tanto exista realmente un "tipo de estudio" definido que sea digno de designarlo como un término especial, no puede ser más indiferente hacia la sociología que lo que la sociología puede serlo hacia aquélla. Si ello no resulta evidente en forma inmediata, lo es, al menos parcialmente, puesto que la mayoría de los etnometodólogos reúnen en un solo conjunto toda una serie de cuestiones que, aunque a veces superponen, son lógicamente separables entre sí. Entre éstas se incluyen el proble- 
ma de la "racionalidad" en la acción y la comunicación; el de la relación entre los conceptos legos y los técnicos, y el de la "indexalidad".

\section{ALGUNAS CRÍTICAS A LA ETNOMETODOLOGIAA}

Como ya habiamos dicho anteriormente, Garfinkel distingue dos tipos globales de "racionalidad", a saber: la de la ciencia y la del sentido común. Sin embargo, para algunos autores, por ejemplo Giddens, esta distinción no es en realidad lógicamente defendible. En primer lugar, ciertos elementos de lo que Garfinkel llama "racionalidades científicas" son necesarias al dar una explicación de la explicabilidad de las acciones, o sea, al hacer inteligible su inteligibilidad. Estos elementos deben estar conectados con los de los mismos actores legos, o el resultado será un gran relativismo. Segundo, el identificar la racionalidad con la "explicabilidad" impide que se realice la descripción de los actos y comunicaciones por medio de un análisis de la conducta motivada con un propósito, es decir, de los esfuerzos de los actores por realizar intereses definidos. Esto explica, al parecer de Giddens, el carácter "vacío" de los informes sobre interacciones y conversaciones que aparece en los escritos de Garfinkel y otros influidos por él. El uso de expresiones tales como hacer la burocracia, "hacer" la física nuclear, el tratarlas como "prácticas ingeniosas", realizaciones prácticas, etc., es por lo tanto, engañoso. El "hacer" una práctica social significa mucho más que volverla explicable, y esto es precisamente lo que la convierte en una realización.

En tanto la actitud de "indiferencia etnometodológica" es mantenida con seriedad, nada puede decirse sobre la relación entre las explicaciones de actores y observadores sobre la acción. Para Garfinkel cada cual es tratado como un miembro, incluso los científicos sociales; la sociología es meramente el razonamiento sociológico práctico de los sociólogos. Ahora bien: podemos aceptar que el científico social está inmerso en el mundo social que trata de descubrir y analizar de un modo particular que es distinto de aquél en que el especialista de las ciencias naturales está inmerso en el suyo. Pero hay un despropósito inherente en el punto de vista de Garfinkel que revela que no puede eludir más que cualquier otro las cuestiones planteadas por la relación entre las explicaciones de los actores y las de los observadores. Esto se demuestra fácilmente si se señala que la etnometodología es en sí misma una hábil práctica que sus adherentes vuelven explicables. Por consiguiente, sería posible adoptar una actitud de "indiferencia etnometodológica" hacia los miembros que hacen la etnometodología; y adoptar una actitud de "indiferencia etnometodológica" hacia estos otros miembros que hacen la etnometodología de la etnometodología; y así sucesivamente hasta el infinito. La misma dificultad reaparece en los escritos de quienes rechazan la postura de la "indiferencia etnometodológica" en favor de un intento de rectificar los que se ven como fracasos del "análisis constructivo". El tema principal reside en que los datos que forman las observaciones en relación con las cuales los sociólogos construyen 
sus teorias e intentan verificarlas depende del "trabajo" previo realizado por los actores legos. La investigación está condicionada por el papel que juegan el conocimiento del sentido común o las "expectativas de fondo" de los actores, en cuanto a definir el fenómeno como fenómeno, por ejemplo, como un "suicidio" o "acto criminal". El observador científico social, de acuerdo con esta idea, estudia las "expectativas de fondo", para lograr una designación válida o "exacta" del fenómeno. Sin embargo, se acepta que lo que los miembros e investigadores rotulan como datos y descubrimientos debe ser entendido con referencia a las expectativas de fondo, pero ¿de quién? Porque si son las del observador aparte de la de los actores involucrados, el resultado es una regresión infinita. Las expectativas de fondo del observador, analizando las expectativas de fondo de los actores, deberían ser analizadas por un segundo observador, que por supuesto recurre a sus propias expectativas de fondo para hacerlo, y asi sucesivamente. Las "perplejidades" no resueltas en el trabajo de algunos de estos autores se manifiestan por el carácter insostenible de las conclusiones a las que son conducidos: por ejemplo, que los fenómenos sociales existen sólo en tanto los actores legos los clasifican o identifican como "existentes". Esto se ejemplifica en proposiciones tan extraordinarias como la afirmación de que, puesto que los "suicidios" son categorizados por los funcionarios antes de ubicarlos en las estadísticas, "no se puede decir correctamente que los suicidios existan (es decir, que sean cosas) mientras no se haya hecho una categorización. Por otra parte, puesto que existen grandes discrepancias entre las partes interesadas en la categorización de casos del mundo real, se puede decir generalmente que los suicidios existen, y no existen al mismo tiempo..." (extraído de A. Giddens, op. cit., 1987).

Para estar en condiciones de extraer los elementos de real interés e importancia de los escritos de Garfinkel, y por lo menos en algunos influidos por él, el círculo lógico en el cual se encierra la etnometodología debe ser sometido a un análisis filosófico más amplio. "No sería exacto, por supuesto, decir que Garfinkel, o los que procuraron aplicar algo de lo que él sostiene sobre la reconstrucción de la "sociología ortodoxa", no toman conciencia de esta circularidad. Por el contrario, parecen adoptar el punto de vista de que ella puede ser aplicada de un modo fecundo" (A. Giddens, op. cit., 1987).

\section{REFLEXIÓN FINAL}

Así como hemos visto en el transcurso del presente trabajo, la etnometodología coloca su atención principalmente en aquellas actividades de la vida cotidiana, en las formas de expresión de los actores "legos" $y$, en definitiva, en una revalorización del denominado conocimiento del "sentido común".

En la etnometodología reside un impulso por interrumpir las rutinas, detener el mundo y el tiempo. Reposa en una percepción del carácter convencional de las reglas subyacentes (o tácitas), donde éstas aparecen como carentes de valor 
intrínseco, como arbitrarias, aunque esenciales para continuar las rutinas. La etnometodología presenta una especie de hostilidad hacia "las cosas tal como son", trata de demostrar la vulnerabilidad del mundo cotidiano a su desorganización mediante la transgresión de esos supuestos tácitos. Por lo tanto, tal como lo indica Gouldner ("La crisis de la sociología occidental", 1970), hay bajo la demostración etnometodológica una especie de impulso anarquista, un anarquismo amable. Tal anarquismo, continúa Gouldner, atraerá, en cierta medida, a la juventud y a otras personas alienadas del statu quo. Permite a los jóvenes alienados desafiar con relativa seguridad al orden establecido, y experimentar su propia potencia. La "demostración" etnometodológica es, en realidad, una especie de microconfrontación con el statu quo y una resistencia no violenta frente a él. Es una rebelión sustitutiva y simbólica contra una estructura global que la juventud no puede, y a menudo no desea, modificar. Sustituye la revolución imposible por la rebelión posible.

Por otra parte, sería adecuado también referirse a la actitud del etnometodólogo hacia el "hombre"; quizás no sea la más adecuada en nuestra época, ya que no aprehende al hombre realmente en su contexto histórico-social, y en su relación con los otros. Por esto resulta de gran importancia pensar en un análisis amplio de lo que es la etnometodología y de las implicaciones que lleva consigo. Esta tarea no resulta fácil, no sólo por la disgresión del material existente al respecto, sino también por la poca difusión que ha tenido esta corriente en nuestro país. Debido a esto, esperamos que el presente trabajo contribuya a lograr esta tarea. 